\title{
The Culturally Competent Counselor: Issues Specific to Four Minority Groups
}

\author{
Gerald Conner, William Walker \\ Department of Behavioral Science, Faulkner University, Montgomery, AL, USA \\ Email:drbwalker@gmail.com
}

How to cite this paper: Conner, G. and Walker, W. (2017) The Culturally Competent Counselor: Issues Specific to Four Minority Groups. Open Journal of Social Sciences, 5, 113-121. https://doi.org/10.4236/jss.2017.53010

Received: February 15, 2017

Accepted: March 14, 2017

Published: March 17, 2017

Copyright $\odot 2017$ by authors and Scientific Research Publishing Inc. This work is licensed under the Creative Commons Attribution International License (CC BY 4.0).

http://creativecommons.org/licenses/by/4.0/

Open Access

\begin{abstract}
Behavioral science helping professionals are ethically obligated to achieve cultural competence in their work with clients. The rapid rise of the minority population in the United States means that helping professionals can expect to work with clients from cultural backgrounds different from their own. This paper examines four cultural groups-African Americans, Hispanics, LGBT, and military veterans, and specific cultural concerns unique to each group. The purpose of the paper is to increase therapist awareness and knowledge of these group-specific cultural issues, thereby contributing to a greater degree of counselor cultural competence.
\end{abstract}

\section{Keywords}

Counselor, Cultural Competence, Minority Groups

\section{Introduction}

Cultural issues continue to be a major focus in the behavioral science helping professions. The dialogue surrounding these issues recognizes the importance of helping professionals being culturally competent in the delivery of therapy services. Cultural competence, as it relates to the behavioral sciences, refers to "...the capacity to draw effectively upon cultural knowledge, awareness, sensitivity, and skillful actions in order to relate appropriately to, and work effectively with, others from different cultural backgrounds" [1].

A primary reason and need for the emphasis on cultural competence is the critical relationship between cultural competence and ethical behavior. Ethical standards exist to benefit the client and to prevent harm. Cultural bias and lack of cultural competency on the part of the helping professional work against any intended benefit to the client and may even result in harm [2] [3]. The APA, ACA, and NASW Code of Ethics all acknowledge the significance of cultural 
competence in the delivery of professional services. The ACA Code of Ethics, for example, states that "...multicultural counseling competency is required across all counseling specialties...” [4].

Enhancement of therapist competence in the behavioral science field has not always been the case. In times past, the attitude has existed that there was a style of therapy (i.e., counseling) called "regular counseling" and a separate, specialized skill area called "multicultural counseling" [5]. The belief was that multicultural counseling was an area of specialty, like addictions or career counseling, chosen only by a subgroup of therapists who desired to "specialize" in this area.

The rapid rise of the minority population in the U.S. makes it increasingly impossible, if not unethical, for the helping profession to treat multicultural counseling as a specialty area. From 2000 to 2010 racial and ethnic minorities accounted for $92 \%$ of the population growth in the United States [6]. Helping professionals can no longer choose to limit their practice to one specific cultural group, nor would it be ethical to do so. In the $21^{\text {st }}$ century, multicultural competence is now a given expectation on the part of all helpers, and rightly so, as multicultural competence is necessary for respecting and understanding the differences that exist in our diverse social structure, society, and worldview [7].

As well, the definition and scope of multicultural counseling competence continue to evolve. No longer limited to issues of nationality or country of origin, multiculturalism now includes ethnicity, race, gender, age, sexual orientation, religion, socioeconomic status, physical ability, mental ability, geographic region, historical experience, and shared experiences that bind people together [8].

Every minority group must deal with cultural issues inherently unique to that group. As challenging as it may be, helping professionals must possess cultural awareness and knowledge specific to the uniqueness of each group to provide a level of treatment that meets ethical standards.

This paper focuses on a representative cross sample of minority groups based on Pedersen's [8] definition (see above). The sampling includes two minority groups whose identity is based on nationality, African Americans and Hispanics; one group whose identity is based on sexual orientation-LGBT; and one group whose identity is based on shared specific experiences-military veterans. The goal is to enlighten helping professionals to some of the unique cultural-related issues common to each of these groups, which, in turn, will result in an increased overall awareness and understanding of how cultural issues influence all minority groups.

\section{Cultural Competency with African-American Clients}

There is a long history of disparity of general health services for African-Americans who represent an underserved vulnerable population in the United States [9]. This disparity is also true of mental health services, as African-Americans are less likely to have access to, seek, and receive mental health treatment [10]. To further best practices in cultural competence, helping professionals should be aware that negative cultural experiences have produced certain negative beliefs 
prejudices, especially towards white social service providers [11].

A hesitancy often exists in the willingness to seek mental health services due to a lack of trust of health system providers [12]. Many African-Americans perceive historically marginalized treatment by the mental health system and inadequately trained providers, largely due to a mental health system that has not understood the experiential stressors of the African-American community [13].

In addition, while physical illness and health problems are freely discussed, thereby generating needed support from family and friends, mental problems often carry a community stigma [14] [15]. This stigma can result in treatment being delayed or not sought at all [16].

The culturally competent helper should be aware that African-Americans are more likely to be misdiagnosed of a mental disorder compared to whites, possibly due to the bias of practitioners who apply different diagnostic rules to African-Americans than they do to white patients [17]. Briggs, et al. [16] make the case that a cultural assessment of African-American clients should be conducted before a clinician assigns a DSM diagnosis. One reason for this is that AfricanAmericans may not present distress in a manner readily recognized by therapists from other cultural backgrounds. Therefore, it becomes essential for counselors to have a knowledge of culturally relevant factors that "permeate or trigger the onset of clinical symptoms or disorders" when working with African-Americans [18].

\section{Cultural Competency with Hispanic Clients}

The Hispanic people in the United States present the fastest growing cultural group, making up $17 \%$ of the U.S. population [19]. This racial group consists of several subgroups including Mexican, Central American, South American, Puerto Rican, Cuban, and Dominican [17].

The Hispanic population presents unique factors for the aspiring culturally competent helper.

Most obvious are language and idiomatic expression barriers [20]. Before the potential client can give informed consent several questions must be considered by the therapist. Is it ethical to enter into a therapy relationship if an English speaking counselor does not speak fluent Spanish, or a Spanish speaking client does not speak fluent English? Is it ethical to enter into a counseling relationship if the client and counselor are just functional in the other's language, but not fluent?

To what degree will level of language comprehension and communication affect quality of services and outcome? Language issues must be satisfactorily addressed before counselor and client can consider entering into a professional relationship.

An issue often unique (but not limited) to Hispanic clients is the stress associated with being an undocumented immigrant. Between 11 and 12 million immigrants are living in the United States illegally, with Hispanics composing 52\% 
of this number [21]. Undocumented Hispanic immigrants may be subject to significant trauma occurring before, during, and after the migration process into the United States. This trauma places them at high risk for mental health problems including posttraumatic stress disorder [22]. Even after arriving in their country of destination there may be continued stress and trauma resulting from discrimination, fear, isolation, and anti-immigration laws. The culturally competent therapist will see this ongoing immigration-related stress as a context for viewing both the client and the client's therapeutic issues [22].

Like African-Americans, Hispanics reportedly underuse mental health services [23]. Reasons for underuse include the fear of being culturally misunderstood, racism, legal fears, costs, distrust, and perceived discomfort with therapy [24]. Therapists should be aware that these issues may impact the therapy relationship, especially during the intake and therapeutic alliance-building stages of therapy.

\section{Cultural Competency with LGBT Clients}

Cultural competence is not limited to ethnic minorities. As defined by Pederson [8], cultural competence may include group cultures identified by behavior, ideals, and alternative lifestyles.

As a historically disenfranchised minority group, the lesbian, gay, bisexual, transgendered (LGBT) community has been the recipients of discrimination, oppression, and sometimes violence. This harmful treatment has been found to be associated with various mental health issues in this population. Perceived discrimination in this group has been positively associated with both harmful effects on quality of life and indicators of psychiatric morbidity [25]. Lesbians and gays have been found to be at high risk for mental disorders such as depression, anxiety, substance abuse, alcoholism, and accompanying comorbidity [26]. LGBT youth have been found to have significantly higher incidence of suicide ideation/attempts compared to heterosexual peers [27].

Many helping professionals lack training in the awareness, knowledge and skills needed to effectively help LGBT clients [28]. Because so, attaining competency with this population should begin with the self of the therapist. A heterosexual therapist must ask her or himself about conflicting personal values and biases with a client who is a member of the LGBT minority-conflicts and biases that could affect standard of care. If the personal values of the therapist conflict with the therapist's professional obligations to LGBT clients the professional should consult with colleagues and supervisors to ensure a course of action that best promotes the welfare of the client. The focus should be on addressing the professional's own biases, skill, or knowledge deficits that might compromise optimal treatment [29]. Other issues of the therapist's "self", include being able to recognize countertransference issues and the ability to deal with attractions to and from same-sex clients [30].

Besides awareness and knowledge, the culturally competent helper needs to possess a skillset that allows for effective intervention with LGBT clients. These 
skills include the ability to make accurate diagnostic assessment of the client within the context of the client's culture [31]. Accurate assessment requires being able to distinguish between symptoms related to intra and interpersonal variables and symptoms related to the pressures of living in a homophobic social environment.

Other skills needed by the counselor include advocacy skills and various skills more practical in nature. As Dixon, Tucker \& Clark well state, "Socially Just counseling and advocacy are expectations in contemporary professional counseling practice in the United States" [32]. The competent multicultural helper must be willing to advocate for the needs and welfare of the LGBT client, just as they would for heterosexual clients [33]. One area where behavioral science professionals can be especially effective as advocates is the area of LGBT mental health. Pandya calls for LGBT mental health issues to be an "advocacy priority", as LGBT individuals are at an increased risk for mental health problems [34]. Other skills include more practical matters such as being skilled in language use (e.g., using terms such as "partner" vs. "husband/wife") in initial phone contacts, intake materials and early assessment questions [35].

\section{Cultural Competency with Military Veteran Clients}

The impact of military involvement in Iraq and Afghanistan has had a farreaching influence on many communities in the United States. More than 2.5 million Americans have been deployed approximately 3.5 million times [36], numbers that increase daily. The likelihood of a helping professional treating a recent veteran is high and demands competence specific to this particular cultural group.

To effectively work with this group the aspiring culturally competent therapist should have an awareness and understanding of the different types of difficulties post-deployment veterans struggle with. These difficulties include reintegration difficulties, family issues, financial problems, substance abuse, posttraumatic stress disorder (PTSD), and medical disability [37].

Perhaps the one issue that has received the most attention with this population is Post Traumatic Stress Disorder [38]. Active symptomology has been reported to be as high as one of every five veterans returning from Iraq and Afghanistan [39]. Ramchand, et al. found approximately one of every two veterans seeking Veterans Administration (VA) treatment tested positive for PTSD [40].

Symptoms of PTSD include re-experiencing the trauma through dreams and flashbacks, distressing thoughts, memories and/or feelings, negative thoughts and mood, sleep disturbance and reckless, aggressive behavior [41]. Helpers must be aware that these symptoms not only adversely affect the veteran but can cause disturbances in the veteran's interpersonal and family relationships [42] [43].

Of great importance, the therapist must be aware of the link between veteran PTSD and suicide. Post-deployed veterans who screened positive for PTSD were more than four times as likely to endorse suicidal ideation compared to non- 
PTSD veterans [44]. Veterans screening positive for PTSD along with two or more comorbid mental disorders were six times to report suicide ideation compared to PTSD-only vets [43]. It is therefore of highest importance that helpers assess combat veterans for combat-related symptoms, including PTSD and suicide ideation.

\section{Conclusion}

Helping professionals today face an increasingly diversified society. This society brings with it an accompanying array of cultural issues specific to each cultural group. An awareness and understanding of these issues is required if helping professionals are to meet their ethical obligations to all clients, regardless of background. This article has discussed cultural issues specific to four minority groups. The intent is that the cultural issues related to these four groups will serve as a template to help counselors learn to develop a cultural awareness and understanding towards all groups of clients.

\section{References}

[1] Sperry, L. (2012) Cultural Competence: A Primer. Journal of Individual Psychology, 68, 310-320.

[2] Siddharth, A. (2012) Ethical Standards for Transnational Mental Health and Psychosocial Support: Do No Harm, Preventing Cross-Cultural Errors and Inviting Pushback. Clinical Social Work Journal, 40, 438-449. https://doi.org/10.1007/s10615-011-0348-z

[3] Sue, D. (2015) Therapeutic Harm and Cultural Oppression. Counseling Psychologist, 43, 359-369. https://doi.org/10.1177/0011000014565713

[4] ACA Code of Ethics (2014) American Counseling Association, Alexandria.

[5] Speight, S., Myers, L., Cox, C. and Highlen, P. (1991) A Redefinition of Multicultural Counseling. Journal of Counseling and Development, 70, 29-36. https://doi.org/10.1002/j.1556-6676.1991.tb01558.x

[6] Passel, J., Cohn, D. and Lopez, M. (2011) Minorities Account for Nearly All US Population Growth. Pew Research Center.

http://www.pewresearch.org/daily-number/minorities-account-for-nearly-all-u-s-p opulation-growth/

[7] Yee, D. and Tursi, C. (2002) Recognizing Diversity and Moving toward Cultural Competence. Generations, 26, 54-58.

[8] Pedersen, P. (2000) Handbook for Developing Multicultural Awareness. 3rd Edition, American Counseling Association, Alexandria.

[9] Kass, B., Weinick, R. and Monheit, A. (1999) MEPS Chartbook. No. 2, Medical Expenditure Survey of the Agency for Health Care Policy and Research, Department of Health and Human Services, Rockville.

[10] Alegría, M., Canino, G., Ríos, R., Vera, M., Calderón, J., Rusch, D. and Ortega, A.N. (2002) Mental Health Care for Latinos: Inequalities in Use of Specialty Mental Health Services among Latinos, African Americans, and Non-Latino Whites. Psychiatric Services, 53, 1547-1555. https://doi.org/10.1176/appi.ps.53.12.1547

[11] Whaley, A.L. and Davis, K.E. (2007) Cultural Competence and Evidence-Based Practice in Mental Health Services: A Complementary Perspective. American Psychologist, 62, 563-574. https://doi.org/10.1037/0003-066X.62.6.563 
[12] Peterson, L. (2002) Racial Differences in Trust. Reaping What We Have Sown? Medical Care, 40, 81-84. https://doi.org/10.1097/00005650-200202000-00002

[13] Diala, C., Muntaner, C., Walrath, C., Nickerson, K., LaViest, T.A. and Leaf, P.J. (2000) Racial Differences in Attitudes toward Professional Mental Health Care and in the Use of Services. American Journal of Orthopsychiatry, 70, 455-464. https://doi.org/10.1037/h0087736

[14] Menke, R. and Flynn, H. (2009) Relationships between Stigma, Depression, and Treatment in White and African American Primary Care Patients. Journal of Nervous and Mental Disease, 197, 407-411. https://doi.org/10.1097/NMD.0b013e3181a6162e

[15] Bradford, L., Newkirk, C. and Holden, K. (2009) Stigma and Mental Health in African Americans. In: Braithwaite, R.L., Taylor, S.E. and Treadwell, H.M., Eds., Health Issues in the Black Community, Jossey-Bass, San Francisco, 119-131.

[16] Briggs, H., Briggs, A., Miller, K. and Paulson, R. (2011) Combating Persistent Cultural Incompetence in Mental Health Systems Serving African Americans. Best Practice in Mental Health, 7, 1-25.

[17] US Department of Health and Human Services (2001) Mental Health: Culture, Race, and Ethnicity. http://www.ncbi.nlm.nih.gov/books/NBK44243/

[18] Whaley, A. (2001) Cultural Mistrust: An Important Psychological Construct for Diagnosis and Treatment of African Americans. Professional Psychology. Research and Practice, 32, 555-562. https://doi.org/10.1037/0735-7028.32.6.555

[19] US Census Bureau (2015) State and County Quick Facts. https://www.census.gov/quickfacts/table/RHI105210/00

[20] Biever, J.L., Teresa, C.M., de las Fuentes, C., González, C., Servín-López, S., Sprowls, C. and Tripp, C.G. (2002) The Role of Language in Training Psychologists to Work with Hispanic Clients. Professional Psychology. Research and Practice, 33, 330-336. https://doi.org/10.1037/0735-7028.33.3.330

[21] Krogstad, J., Passel, J.S. and Cohn, D. (2016) 5 Facts about Illegal Immigration in the US Pew Research Center.

http://www.pewresearch.org/fact-tank/2016/11/03/5-facts-about-illegal-immigratio n-in-the-u-s/

[22] Salas, L., Ayon, C. and Gurrola, M. (2013) Estamos Traumados: The Effect of Anti-Immigrant Sentiment and Policies on the Mental Health of Mexican Immigrant Families. Journal of Community Psychology, 41, 1005-1021. https://doi.org/10.1002/jcop.21589

[23] Ruiz, P. and Langrod, J. (2004) Hispanic Americans. In: Lowisoin, J., Ruiz, P., Millman, R. and Langrod, J., Eds., Substance Abuse: A Comprehensive Textbook, Lippincott Williams \& Wilkins, Baltimore, 1103-1112.

[24] Rastogi, M., Massey-Hastings, N. and Wieling, E. (2012) Barriers to Seeking Mental Health Services in the Latino/a Community: A Qualitative Analysis. Journal of Systemic Therapies, 31, 1-17. https://doi.org/10.1521/jsyt.2012.31.4.1

[25] Mays, V. and Cochran, S. (2001) Mental Health Correlates of Perceived Discrimination among Lesbian, Gay, and Bisexual Adults in the United States. American Journal of Public Health, 91, 1869-1876. https://doi.org/10.2105/AJPH.91.11.1869

[26] Sherry, A., Adelman, A., Whilde, M. and Quick, D. (2010) Competing Selves: Negotiating the Intersection of Spiritual and Sexual Identities. Professional Psychology: Research and Practice, 41, 112-119. https://doi.org/10.1037/a0017471

[27] Haas, A., Eliason, M., Mays, V., Mathy, R., Cochran, S., D’Augelli, A. and Clayton, P. (2011) Suicide and Suicide Risk in Lesbian, Gay, Bisexual, and Transgender Pop- 
ulations: Review and Recommendations. Journal of Homosexuality, 58, 10-51. https://doi.org/10.1080/00918369.2011.534038

[28] Lyons, H., Bieschke, K., Dendy, A., Worthington, R. and Georgemiller, R. (2010) Psychologists' Competence to Treat Lesbian, Gay and Bisexual Clients: State of the Field and Strategies for Improvement. Professional Psychology: Research and Practice, 41, 424-434. https://doi.org/10.1037/a0021121

[29] Association for Lesbian, Gay, Bisexual, and Transgender Issues in Counseling (2013) Competencies for Counseling with Lesbian, Gay, Bisexual, Queer, Questioning, Intersex and Ally Individuals. Journal of LGBT Issues in Counseling, 7, 2-43.

[30] Hacock, K.A. (2000) Lesbian, Gay, and Bisexual Lives: Basic Issues in Psychotherapy Training and Practice. In: Greene, B. and Croom, G.L., Eds., Education, Research and Practice in Lesbian, Gay, Bisexual, and Transgendered Psychology, Sage, Thousand Oaks, 91-130. https://doi.org/10.4135/9781452233697.n5

[31] Arredondo, P. (1999) Multicultural Counseling Competencies as Tools to Address Oppression and Racism. Journal of Counseling and Development, 77, 102-108. https://doi.org/10.1002/j.1556-6676.1999.tb02427.x

[32] Dixon, A., Tucker, C. and Clark, M. (2010) Integrating Social Justice Advocacy with National Standards of Practice: Implications for School Counselor Education. Counselor Education \& Supervision, 50, 103-115. https://doi.org/10.1002/j.1556-6978.2010.tb00112.x

[33] Israel, T., Ketz, K., Detrie, P., Burke, M. and Shulman, J. (2003) Identifying Counselor Competencies for Working with Lesbian, Gay, and Bisexual Clients. Journal of Gay and Lesbian Psychotherapy, 7, 3-21. https://doi.org/10.1300/J236v07n04_02

[34] Pandya, A. (2014) Mental Health as an Advocacy Priority in the Lesbian, Gay, Bisexual, and Transgender Communities. Journal of Psychiatric Practice, 20, 225-227. https://doi.org/10.1097/01.pra.0000450322.06612.a1

[35] Division 44/Committee on Lesbian, Gay, and Bisexual Concerns Joint Task Force on Guidelines for Psychotherapy with Lesbian, Gay, and Bisexual Clients. (2000) Guidelines for Psychotherapy with Lesbian, Gay, and Bisexual Clients. American Psychologist, 55, 1440-1451. https://doi.org/10.1037/0003-066X.55.12.1440

[36] Engel, C.C. (2014) Military and Veteran Mental Health: Why Should Psychiatrists Care?

http://www.psychiatrictimes.com/military-mental-health/military-and-veteran-men tal-health-why-should-psychiatrists-care

[37] Carrola, P. and Corbin-Burdick, M.F. (2015) Counseling Military Veterans: Advocating for Culturally Competent and Holistic Interventions. Journal of Mental Health Counseling, 37, 1-14. https://doi.org/10.17744/mehc.37.1.v74514163rv73274

[38] Seal, K.H., Metzler, T.J., Gima, K.S., Bertenthal, D., Maguen, S. and Marmar, C.R. (2009) Trends and Risk Factors for Mental Health Diagnoses among Iraq and Afghanistan Veterans Using Department of Veterans Affairs Health Care, 2002-2008. American Journal of Public Health, 99, 1651-1658.

https://doi.org/10.2105/AJPH.2008.150284

[39] Burriss, L., Ayers, E., Ginsberg, J. and Powell, D. (2008) Learning and Memory Impairment in PTSD: Relationship to Depression. Depression and Anxiety, 25, 149157. https://doi.org/10.1002/da.20291

[40] Ramchand, R., Schell, T.L., Karney, B.R., Osilla, K.C., Burns, R.M. and Caldarone, L.B. (2010) Disparate Prevalence Estimates of PTSD among Service Members Who Served in Iraq and Afghanistan: Possible Explanations. Journal of Traumatic Stress, 23, 59-68. https://doi.org/10.1002/jts.20486 
[41] American Psychiatric Association (2013) Post-Traumatic Stress Disorder. Diagnostic and Statistical Manual of Mental Disorders, 5th Edition, American Psychiatric Publishing, Arlington.

[42] McFarlane, A. and Bookless, C. (2001) The Effect of PTSD on Interpersonal Relationships: Issues for Emergency Service Workers. Sexual and Relationship Therapy, 16, 261-267. https://doi.org/10.1080/14681990124457

[43] Galovski, T. and Lyons, J. (2004) Psychological Sequelae of Combat Violence: A Review of the Impact of PTSD on the Veteran's Family and Possible Interventions. Aggression and Violent Behavior, 9, 477-501. https://doi.org/10.1016/S1359-1789(03)00045-4

[44] Jakupcak, M., Cook, J., Imel, Z., Fontana, A., Rosenheck, R. and McFall, M. (2009) Posttraumatic Stress Disorder as a Risk Factor for Suicidal Ideation in Iraq and Afghanistan War Veterans. Journal of Traumatic Stress, 22, 303-306.

https://doi.org/10.1002/jts.20423

\section{Scientific Research Publishing}

Submit or recommend next manuscript to SCIRP and we will provide best service for you:

Accepting pre-submission inquiries through Email, Facebook, LinkedIn, Twitter, etc. A wide selection of journals (inclusive of 9 subjects, more than 200 journals)

Providing 24-hour high-quality service

User-friendly online submission system

Fair and swift peer-review system

Efficient typesetting and proofreading procedure

Display of the result of downloads and visits, as well as the number of cited articles

Maximum dissemination of your research work

Submit your manuscript at: http://papersubmission.scirp.org/

Or contact jss@scirp.org 